\title{
Studies on the Design and Synthesis of New Monocyclic $\beta$-Lactams Containing Substructures of Penicillin G
}

\author{
Sang Hyup Lee \\ College of Pharmacy, Duksung Women's University, Seoul 132-714, Korea.E-mail: sanghyup@duksung.ac.kr \\ Received May 16, 2014, Accepted June 15, 2014
}

\begin{abstract}
The studies on design and synthesis of new monocyclic $\beta$-lactam esters $4(R / S)$-(1'-methoxycarbonylpropyl$2^{\prime}(R / S)$-thio)-3(R)-phenylacetamidoazetidin-2-one (3a) and 4(R/S)-(1'-methoxycarbonyl-2'-methyl-propyl-2'thio)-3(R)-phenylacetamidoazetidin-2-one (3b) were described. Compounds $\mathbf{3 a}$ and $\mathbf{3 b}$ were specifically designed to retain all penicillin substructures except the bicyclic system, which would be conceived by cleaving the $\mathrm{C}(3)-\mathrm{N}(4)$ bond of penicillin $\mathrm{G}$. Compounds $\mathbf{3} \mathbf{a}$ and $\mathbf{3} \mathbf{b}$ are of particular interest in the context of the structural elucidation of monocyclic $\beta$-lactams originated from penicillin. Key intermediates, $\beta$-mercapto esters $6 \mathbf{a}$ and $\mathbf{6 b}$, were synthesized from conjugate acids $4 \mathbf{a}$ and $\mathbf{4 b}$ using three-step synthetic sequences, respectively, and 4(S)-acetoxy-3(S)-phenylacetamidoazetidin-2-one (7) was obtained from the degradation of penicillin G. Reactions of $\mathbf{6 a}$ and $\mathbf{6 b}$ with 7 , thus obtained, provided the target compounds $\mathbf{3 a}$ and $\mathbf{3 b}$, respectively.
\end{abstract}

Key Words : Monocyclic $\beta$-lactams, 3-mercaptobutanoate, Acetylthio, Azetidinone

\section{Introduction}

Of the diverse compounds that display antibacterial activities, $\beta$-lactams are still considered valuable antibiotics. In particular, the monocyclic $\beta$-lactam series ${ }^{1,2}$ are considered to represent a class of compounds separate from the classical bicyclic $\beta$-lactams. Monocyclic $\beta$-lactams are known to exhibit unique physical and chemical properties due to their structural features. For examples, monocyclic $\beta$ lactam compounds including Aztreonam (1) ${ }^{3}$ that contains a 1-sulfonate group and a 3-acylamido side chain have been reported to display good antibacterial ${ }^{2,3}$ and non-antibacterial activities. ${ }^{4,5}$ These characteristics represent the potential use of the monocyclic $\beta$-lactams, as has been previously described in a review paper. ${ }^{6}$

However, some of the monocyclic $\beta$-lactams still suffer from chemical instabilities and narrow spectrum of activities. Despite the extensive efforts to improve these features, much remains unknown. Moreover, further studies are required to determine the effects of substituents on physicochemical and biological properties of these compounds. In this regard, we previously reported the design and synthesis of interesting monocyclic $\beta$-lactams 2 . $^{7}$

As a part of our continual work to explore the features of monocyclic $\beta$-lactams, we here report the studies on design

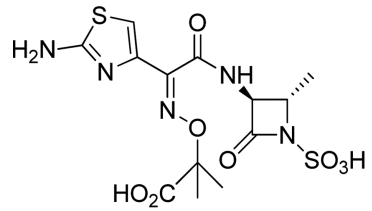

1

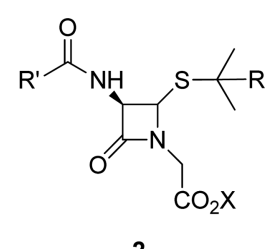

2
Figure 1. Structures of monocyclic $\beta$-lactams $\mathbf{1}$ and $\mathbf{2}$.

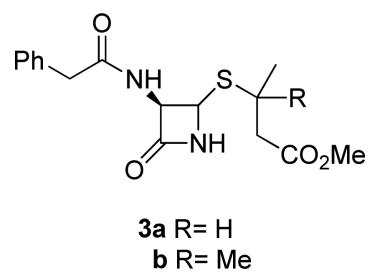

Figure 2. Structures of monocyclic $\beta$-lactams $\mathbf{3 a}$ and $\mathbf{3 b}$.

and synthesis of new monocyclic $\beta$-lactam esters $\mathbf{3 a}$ and $\mathbf{3 b}$ as prodrugs derived from the cleavage of the bicyclic system of penicillin while retaining its substructures.

\section{Results and Discussion}

Design and Structural Features of 3a and 3b. We wished to generate new monocyclic $\beta$-lactams by the strategy of opening the bicyclic system in penicillin structure. Of the several ways of opening the thiazolidine ring of the penicillin, we focused on cleavage of the $\mathrm{C}(2)-\mathrm{C}(3)$ bond (path $A$ ) and $\mathrm{C}(3)-\mathrm{N}(4)$ bond (path $B$ ). Previously, we described the monocyclic $\beta$-lactams 2 obtained by cleavage path $A .^{7}$ In the present study, we designed new monocyclic $\beta$-lactams 3 resulting from cleavage path $B$, and the retention of all penicillin substructures except the thiazolidine ring system. In particular, there is no substituent at N(1) of the $\beta$-lactam ring and this secondary amide structure could cause chemical and metabolic instability, which is of our interest to modulate their stability and reactivity. In addition, compounds $\mathbf{3 a}$ and $\mathbf{3 b}$ have a phenylacetamido group at $\mathrm{C}(3)$ as an acyl side chain, and a secondary (e.g., 3a) or tertiary alkylthio group (e.g., 3b) at $\mathrm{C}(4)$. The carboxylate group was also retained with structural similarity, but interestingly, the carboxylic acid ester group was tethered at $\mathrm{C}(4)$ through the alkylthio 

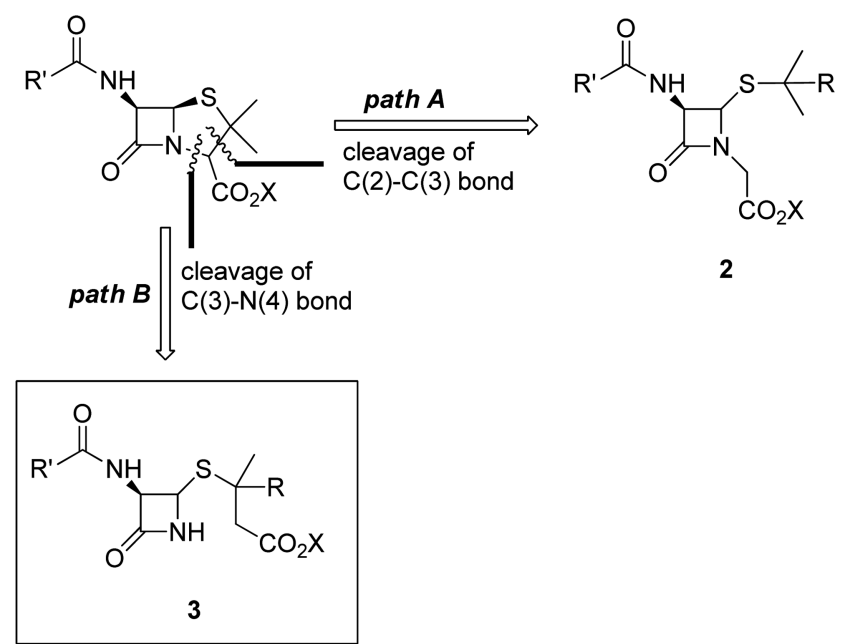

Figure 3. Cleavage paths $\mathrm{A}$ and $\mathrm{B}$ of penicillin.

linker. Based on the expectation that methyl ester would be one of the well-known forms as prodrug esters, and might improve the absorption and pharmacokinetic profiles, ${ }^{8,9}$ we chose methyl esters for our compounds. Taken together, 3a and 3b seemed to contain all penicillin substructures except for the bicyclic ring system. Thus, we consider that the $\beta$ lactam ring in $\mathbf{3}$ would be less-strained and less-substituted, but more unstable and reactive than the $\beta$-lactam ring in penicillin. Resultantly, we consider that $\mathbf{3 a}$ and $\mathbf{3 b}$ could be interesting analogues for the structural elucidation of monocyclic $\beta$-lactams obtained from the breakdown of penicillin.

Synthesis of Monocyclic $\beta$-Lactams 3a and 3b. We considered several pathways to synthesize the target compounds 3a and $\mathbf{3 b}$. The use of acetoxyazetidinone ${ }^{10}$ was of particular interest because we confirmed in our previous studies ${ }^{7}$ that the acetoxy group in acetoxyazetidinone can be replaced by the secondary or tertiary thiols in reasonable yields. Therefore, we devised a synthetic scheme to synthesize $\mathbf{3 a}$ and $\mathbf{3 b}$ using the corresponding thiols $\mathbf{6 a}$ and $\mathbf{6 b}$ as key intermediates, respectively, as shown in Scheme 1. In order to synthesize key thiol intermediates $6 \mathbf{a}$ and $\mathbf{6 b}$ that have a $\beta$ mercapto ester (or acid), we have considered several methods, and tested their feasibilities by carrying out the corresponding reactions. To introduce sulfur atom at the $\beta$-carbon, we attempted to induce the conjugate addition of hydrogen bromide to an $\alpha, \beta$-unsaturated ester (or acid) to give a $\beta$ bromo ester (or acid), which then was expected to be displaced by sulfur nucleophiles to give the appropriate $\beta$ mercapto ester (or acid). However, conjugate addition and displacement did not provide satisfactory results. Next, we attempted the conjugate addition of arylthiols ${ }^{11}$ to $\alpha, \beta$ unsaturated ester (or acid), but again results were unsatisfactory. In addition, according to the reports regarding the use of phenylthiomagnesium iodide, ${ }^{12}$ conjugate addition of acetylthiomagnesium iodide to $\alpha, \beta$-unsaturated ester was conducted, but products were obtained at low levels only. We then considered the conjugate addition of thiolacetic acid followed by selective scission of the S-C bond to afford $\beta$ mercapto ester (or acid). Although it has been reported that

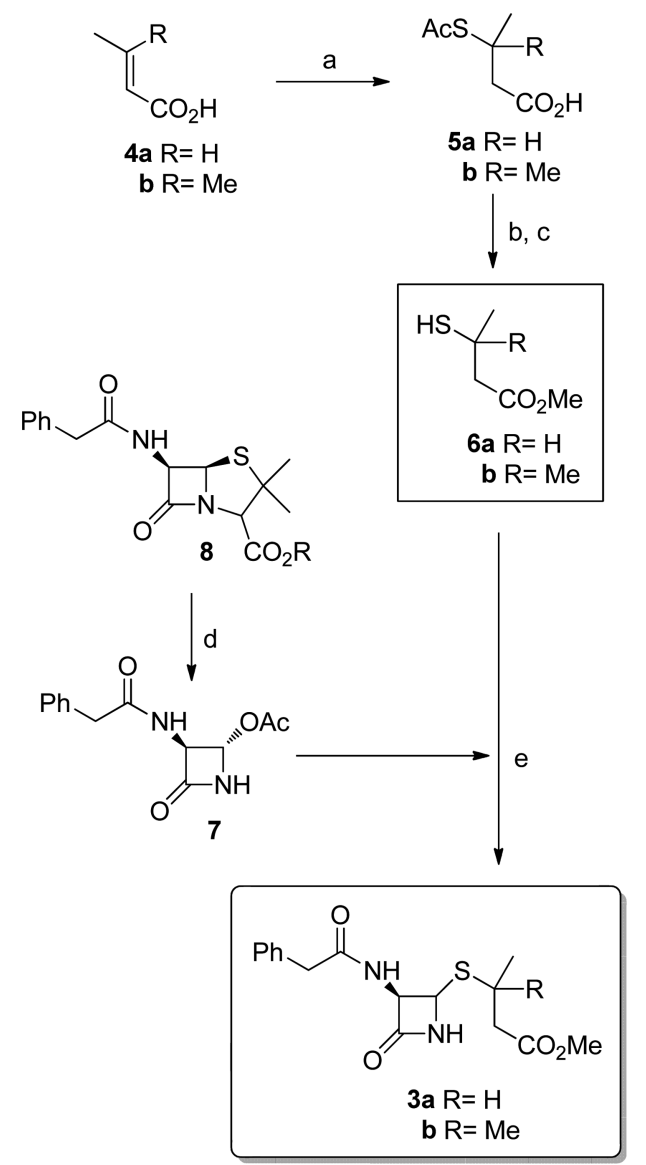

Scheme 1. Synthesis of monocyclic $\beta$-lactams 3. Reagents and conditions: (a) AcSH, room temperature, $16 \mathrm{~h}, 82 \%$ (for $\mathbf{5 a}$ ), and $25 \%$ (for 5b); (b) $p$ - $\mathrm{TsOH}, \mathrm{MeOH}$, room temperature, $7 \mathrm{~h}$; then, (c) $\mathrm{K}_{2} \mathrm{CO}_{3}$, room temperature, $30 \mathrm{~min}, 80 \%$ (for $\mathbf{6 a}$ ), and $57 \%$ (for $\mathbf{6 b}$ ) for two steps; (d) $\mathrm{PhCH}_{2} \mathrm{Br}, \mathrm{DMF}, 2 \mathrm{~h}$; then, $\mathrm{Hg}(\mathrm{OAc})_{2}, \mathrm{AcOH}$, $\mathrm{Ac}_{2} \mathrm{O}, 80^{\circ} \mathrm{C}, 2 \mathrm{~h}$; then, $\mathrm{O}_{3}$, methanol- $\mathrm{CH}_{2} \mathrm{Cl}_{2}, \mathrm{Me}_{2} \mathrm{~S},-78^{\circ} \mathrm{C}, 2 \mathrm{~h}$, $40 \%$ (for three steps); (e) NaH, THF, room temperature, $7 \mathrm{~h}$, then, $60{ }^{\circ} \mathrm{C}, 3 \mathrm{~h}, 31 \%$ (for $3 \mathbf{a}$ ), and $17 \%$ (for $3 \mathbf{b}$ ).

thiolacetic acid adds rapidly to $\alpha, \beta$-unsaturated ketones ${ }^{13}$ and slowly to $\alpha, \beta$-unsaturated acids, ${ }^{14}$ we attempted this reaction using $\alpha, \beta$-unsaturated acid for our synthesis.

After examining several conditions to incorporate acetylthio group at $\beta$-position to carbonyl, we treated crotonic acid (4a) with thiolacetic acid, and obtained 3-acetylthiobutanoic acid $(\mathbf{5 a})^{15}$ in $82 \%$ yield. Subsequently, 5a was esterified using $p$-toluenesulfonic acid as catalyst in $\mathrm{MeOH}$ to give the corresponding methyl ester, which was then selectively hydrolyzed by potassium carbonate ${ }^{16}$ to afford the key intermediate, methyl 3-mercaptobutanoate $(\mathbf{6 a})^{17}$ in $80 \%$ yield. As a result, 6a was synthesized from 4a through a three-step sequence in $66 \%$ yield. In a similar manner, another key intermediate, methyl 3-mercapto-3-methylbutanoate (6b), was also synthesized from $\mathbf{4 b}$, via $\mathbf{5 b},{ }^{18}$ through a three-step sequence in $14 \%$ yield. Notably, the yield of $\mathbf{6 a}$ was found to be much better than that of $\mathbf{6 b}$, which suggested that in the first step, addition of thiolacetic acid to the conjugate acid 4 was greatly influenced by the presence of an additional substituent at the $\beta$-position of the conjugate acid. Thus, we 
considered that as $\mathbf{4 a}$ was a less-hindered conjugate acid for addition, it provided a higher yield than $\mathbf{4 b}$.

We then investigated the displacement of the acetoxy group in azetidinone with a thiol group, and as a model study, we performed the reaction using 4-acetoxyazetidin-2one $(9)^{7,19}$ which was obtained by reacting vinyl acetate and chlorosulfonyl isocyanate. Accordingly, the $\beta$-mercapto ester 6a was treated with sodium hydride and then reacted with 9 to give the corresponding 4-alkylthioazetidin-2-one in moderate yields $(\sim 50 \%)$. However, extensive efforts to improve the yield of this reaction using Lewis acids, such as, zinc chloride and borontrifluoride etherate ${ }^{13}$ were unsuccessful.

Given the results of the model study, we investigated the reaction of $\beta$-mercapto esters $\mathbf{6 a}$ and $\mathbf{6 b}$ with the acetoxyazetidinone derivative 7.,20 Compound 7 was prepared from penicillin $\mathrm{G}$ through a three-step sequence in $40 \%$ yield, using the procedure described in our previous studies. ${ }^{7}$ Then, $\beta$-mercapto ester $\mathbf{6 a}$ or $\mathbf{6 b}$ was mixed with sodium hydride at room temperature for $1 \mathrm{~h}$, and further treated with 7 , to produce $\mathbf{3 a}$ or $\mathbf{3 b}$, respectively. Regarding the stereochemistry of these compounds, three chiral carbons exist in $\mathbf{3 a}$ and two in $\mathbf{3 b}$, and of these, one chiral carbon $(\mathrm{C}(3))$ in both compounds has a fixed $R$-configuration. Thus, there could be four isomers (two cis- and two trans-isomers) for $\mathbf{3 a}$ and two isomers (cis- and trans-isomers) for $\mathbf{3 b}$. In the case of $\mathbf{3 a}$, two isomer sets (cis/trans) were isolated and identified, regardless of considerations of the chirality in the $\beta$-carbon of ester side chain. In the case of $\mathbf{3 b}$, the two isomers (cis/trans) were also isolated and identified. The stereochemistries of cis-/trans-isomers were determined using the chemical shift values $(\delta)$ and coupling constants $(J)$ of $\mathrm{C}(3) \mathrm{H}$ and $\mathrm{C}(4) \mathrm{H}$ signals in ${ }^{1} \mathrm{H}$ NMR. ${ }^{21,22}$ Accordingly, we investigated the ratios of cis-/trans-isomer formed in different reaction conditions, and the results were shown in Table 1.

The reactions provided compound 3a in ratios ranging from $2.5: 1$ to $1: 1$ and compound $\mathbf{3 b}$ in a ratio of $3: 1$. In general, relatively poor yields were obtained and greater difficulties were encountered in the case of tertiary mercaptan (e.g., 3b). More specifically, the ratios of cis-/transisomer of 3a changed from 2.5:1 (room temperature, $3 \mathrm{~h}$ ) to $1: 1\left(60^{\circ} \mathrm{C}, 3 \mathrm{~h}\right)$, and the ratio of $3 \mathbf{b}$ was $3: 1\left(60^{\circ} \mathrm{C}, 3 \mathrm{~h}\right)$. Results obtained for 3a showed that at room temperature the cis-isomer prevails over the trans-isomer, probably due to the effect of $\mathrm{S}_{\mathrm{N}} 2$-type nucleophilic displacement. ${ }^{23}$ However, as reaction temperature increased and/or reaction time elongated, the ratio of trans-isomer increased due to its

Table 1. Reactions of $\mathbf{6}$ and 7 to give 3

\begin{tabular}{ccccc}
\hline Reactants & $\begin{array}{c}\text { Temp. } \\
\left({ }^{\circ} \mathrm{C}\right)\end{array}$ & $\begin{array}{c}\text { Time } \\
(\mathrm{h})\end{array}$ & Product & $\begin{array}{c}\text { Ratio } \\
(\text { cis/trans })\end{array}$ \\
\hline $\mathbf{6 a}$ & $\mathrm{rt}$ & 3.0 & $\mathbf{3 a}$ & $2.5: 1$ \\
$\mathbf{6 a}$ & 60 & 1.5 & $\mathbf{3 a}$ & $1.5: 1$ \\
$\mathbf{6 a}$ & 60 & 3.0 & $\mathbf{3 a}$ & $1: 1$ \\
$\mathbf{6 b}$ & 60 & 3.0 & $\mathbf{3 b}$ & $3: 1$ \\
\hline
\end{tabular}

thermodynamic stability of trans-isomer. Notably, we observed the formation of trans-isomer that could be formed only via a $\mathrm{S}_{\mathrm{N}}$ 1-type reaction, which derives some support from the previous studies on the involvement of intermediate, such as, the iminium ion. ${ }^{24}$ Taken together, the final yields for $\mathbf{3 a}$ and $\mathbf{3 b}$ were found to be $31 \%$ and $17 \%\left(60^{\circ} \mathrm{C}, 3 \mathrm{~h}\right)$, respectively.

\section{Conclusion}

We report the studies on design and synthesis of the new monocyclic $\beta$-lactam esters 3a and $\mathbf{3 b}$. Compounds 3a and 3b were designed by the scission of $\mathrm{C}(3)-\mathrm{N}(4)$ bond of penicillin $\mathrm{G}$ structure, thereby aiming to retain all penicillin substructures except for the bicyclic ring system. These compounds have a phenylacetamido group as a side chain at $\mathrm{C}(3)$ but no substituent at N(1). Compounds $\mathbf{3 a}$ and $\mathbf{3 b}$ also have an alkylthio group at $\mathrm{C}(4)$ that contains a carboxylic acid ester group two carbons away from sulfur, leading to incorporation of a sec- or tert-thiol, respectively. Taken together, association of these moieties would represent the whole structure of penicillin $\mathrm{G}$ except bicyclic ring structure. Synthesis of $\mathbf{3}$ was achieved from the synthesis of key intermediates $\mathbf{6}$. Compounds $\mathbf{6 a}$ and $\mathbf{6 b}$ were synthesized from $4 \mathbf{a}$ and $\mathbf{4 b}$ through each three-step synthetic sequence in $66 \%$ and $14 \%$ yields, respectively. Intermediates $\mathbf{6 a}$ and 6b were reacted with the acetoxyazetidinone derivative 7 , which was prepared by the degradation of penicillin $\mathbf{8}$, to produce $\mathbf{3} \mathbf{a}$ and $\mathbf{3 b}$ in moderate yields.

\section{Experimental}

General. Infrared (IR) spectra were obtained using a Perkin-Elmer 267 spectrometer and frequencies $(v)$ are given in reciprocal centimeters $\left(\mathrm{cm}^{-1}\right)$. ${ }^{1} \mathrm{H}$ NMR spectra were obtained using a Varian FT-80A Spectrometer and $\delta$ values for chemical shifts are expressed as units relative to tetramethylsilane (TMS). Analytical thin layer chromatography (TLC) was conducted on glass plates $(0.25 \mathrm{~mm})$ coated with silica gel 60F-254 (Merck). Column chromatography was performed using Merck silica gels (0.040-0.063 mm). Most chemicals were purchased commercially and, when needed, were distilled before use. Some compounds were prepared by known procedures and identified by comparing spectral and physical data with reported values.

3(R/S)-Acetylthiobutanoic Acid (5a) ${ }^{15}$ and 3-Acetylthio3-methylbutanoic Acid (5b). ${ }^{18}$ A solution of crotonic acid (4a, $3.2 \mathrm{~g}, 37 \mathrm{mmol})$ and thiolacetic acid $(5.3 \mathrm{~mL}, 74 \mathrm{mmol})$ was maintained at room temperature for $16 \mathrm{~h}$. Excess thiolacetic acid was removed in vacuo. The remained residue was treated with $\mathrm{H}_{2} \mathrm{O}(50 \mathrm{~mL})$ and the mixture was extracted with EtOAc $(2 \times 50 \mathrm{~mL})$. The combined organic layers were dried over $\mathrm{MgSO}_{4}$, filtered, and concentrated in vacuo to give an oily residue. Purification of the residue by column chromatography afforded the title compound (5a, $4.9 \mathrm{~g}, 82 \%$ ) as a yellow solid. Similarly, the use of 3-methylcrotonic acid (4b, $3.7 \mathrm{~g}, 37 \mathrm{mmol})$ as a starting material 
afforded the title compound $(\mathbf{5 b}, 1.6 \mathrm{~g}, 25 \%)$ as a yellow solid. For 5a: ${ }^{1} \mathrm{H}$ NMR $\left(\mathrm{CDCl}_{3}, 80 \mathrm{MHz}\right) \delta 10.0($ br s, $1 \mathrm{H})$, 3.90-3.70 (m, 1H), 2.75-2.56 (m, 2H), $2.29(\mathrm{~s}, 3 \mathrm{H}), 1.40(\mathrm{~d}$, $J=7.0 \mathrm{~Hz}, 3 \mathrm{H})$; IR $\left(\mathrm{CHCl}_{3}\right) \vee 3150,1720,1700 \mathrm{~cm}^{-1}$.

Methyl 3(R/S)-Mercaptobutanoate (6a) ${ }^{17}$ and Methyl 3Mercapto-3-methylbutanoate (6b). To a stirred solution of 3 -acetylthiobutanoic acid $(\mathbf{5 a}, 2.1 \mathrm{~g}, 13 \mathrm{mmol})$ in methanol $(40 \mathrm{~mL})$ was added $p$-toluenesulfonic acid monohydrate $(0.19 \mathrm{~g}, 1.0 \mathrm{mmol})$ at room temperature. After stirring for 7 $\mathrm{h}, \mathrm{K}_{2} \mathrm{CO}_{3}(7.2 \mathrm{~g}, 52 \mathrm{mmol})$ was added in small portions at room temperature and stirring was continued for $30 \mathrm{~min}$. Then, solvent was removed in vacuo and the residue so obtained was poured onto $50 \mathrm{~mL}$ of $\mathrm{H}_{2} \mathrm{O}$, which was adjusted to $\mathrm{pH} 3.0$ with aqueous $1.0 \mathrm{~N} \mathrm{HCl}$. The mixture was extracted with $\mathrm{CH}_{2} \mathrm{Cl}_{2}(3 \times 40 \mathrm{~mL})$ and the organic layers were combined, dried over $\mathrm{MgSO}_{4}$, filtered, and concentrated in vacuo to give an oily residue. Purification of the residue by Kugel Rohr vacuum distillation $\left(\mathrm{mp} 58-63{ }^{\circ} \mathrm{C} / 30\right.$ $\mathrm{mmHg}$ ) afforded the title compound $(\mathbf{6 a}, 1.4 \mathrm{~g}, 80 \%)$ as a sticky solid. Similarly, the use of 3-acetylthio-3-methylbutanoic acid $(\mathbf{5 b}, 2.3 \mathrm{~g}, 13 \mathrm{mmol})$ as a starting material afforded the title compound $(6 \mathbf{b}, 1.1 \mathrm{~g}, 57 \%)$ as a sticky solid. For 6a: ${ }^{1} \mathrm{H}$ NMR $\left(\mathrm{CDCl}_{3}, 80 \mathrm{MHz}\right) \delta 3.63(\mathrm{~s}, 3 \mathrm{H})$, $3.63-3.10(\mathrm{~m}, 1 \mathrm{H}), 2.55(\mathrm{~d}, J=7.5 \mathrm{~Hz}, 2 \mathrm{H}), 1.77(\mathrm{~d}, J=7.0$ $\mathrm{Hz}, 1 \mathrm{H}), 1.41(\mathrm{~d}, J=7.0 \mathrm{~Hz}, 3 \mathrm{H})$; IR (KBr) $v 1750 \mathrm{~cm}^{-1}$.

4(R/S)-(1'-Methoxycarbonylpropyl-2' $(R / S)$-thio)-3(R)phenylacetamidoazetidin-2-one (cis/trans-3a). To a stirred solution of $\mathrm{NaH}(41 \mathrm{mg}, 1.7 \mathrm{mmol})$ in THF $(5 \mathrm{~mL})$ at room temperature was added a solution of methyl 3-mercaptobutanoate $(\mathbf{6 a}, 228 \mathrm{mg}, 1.7 \mathrm{mmol})$ in THF $(1.5 \mathrm{~mL})$. After stirring for $1 \mathrm{~h}$ at room temperature, a solution of the azetidinone derivative $(7,370 \mathrm{mg}, 1.4 \mathrm{mmol})$ in THF $(2 \mathrm{~mL})$ was added to the mixture, which was then stirred for additional 3 $\mathrm{h}$ at $60{ }^{\circ} \mathrm{C}$. After cooling, the reaction mixture was treated with $\mathrm{H}_{2} \mathrm{O}(30 \mathrm{~mL})$ and extracted with $\mathrm{CH}_{2} \mathrm{Cl}_{2}(2 \times 30 \mathrm{~mL})$, and the organic layers were washed with $5 \%$ brine $(2 \times 20$ $\mathrm{mL}$ ). The combined organic layers were dried over $\mathrm{MgSO}_{4}$, filtered, and concentrated in vacuo to give an oily residue. Purification of the residue by column chromatography afforded the title compound (3a, $146 \mathrm{mg}, 31 \%$, cis-/transisomer $=1 / 1) .{ }^{1} \mathrm{H}$ NMR $\left(\mathrm{CDCl}_{3}, 80 \mathrm{MHz}\right)$, for cis-3a: $\delta 7.20$ (s, 5H), 7.05 (br s, 1H), $6.90(\mathrm{~d}, J=7.0 \mathrm{~Hz}, 1 \mathrm{H}), 4.92-4.70$ $(\mathrm{m}, 1 \mathrm{H}), 4.50(\mathrm{dd}, J=8.0,2.0 \mathrm{~Hz}, 1 \mathrm{H}), 3.60(\mathrm{~s}, 3 \mathrm{H}), 3.50(\mathrm{~s}$, $2 \mathrm{H}), 3.45-3.05(\mathrm{~m}, 1 \mathrm{H}), 2.51(\mathrm{~d}, J=6.5 \mathrm{~Hz}, 2 \mathrm{H}), 1.30(\mathrm{~d}, J$ $=6.5 \mathrm{~Hz}, 3 \mathrm{H})$; for trans-3a: $\delta 7.26(\mathrm{~s}, 5 \mathrm{H}), 7.00(\mathrm{br} \mathrm{s}, 1 \mathrm{H})$, $6.85(\mathrm{~d}, J=7.0 \mathrm{~Hz} .1 \mathrm{H}), 5.49$ (dd, $J=9.0,5.0 \mathrm{~Hz}, 1 \mathrm{H}), 5.07$ (dd, $J=5.0,2.0 \mathrm{~Hz}, 1 \mathrm{H}), 3.65(\mathrm{~s}, 3 \mathrm{H}), 3.60(\mathrm{~s}, 2 \mathrm{H}), 3.30$ $3.10(\mathrm{~m}, 1 \mathrm{H}), 2.55-2.33(\mathrm{~m}, 2 \mathrm{H}), 1.30-1.20(\mathrm{~m}, 3 \mathrm{H})$; IR $(\mathrm{KBr}) \vee 3400,1780,1745,1685 \mathrm{~cm}^{-1}$.

4(R/S)-(1'-Methoxycarbonyl-2'-methylpropyl-2'-thio)3(R)-phenylacetamidoazetidin-2-one (cis/trans-3b). To a stirred solution of $\mathrm{NaH}(7.5 \mathrm{mg}, 0.31 \mathrm{mmol})$ in THF $(2 \mathrm{~mL})$ at room temperature was added a solution of methyl 3mercapto-3-methylbutanoate $(\mathbf{6 b}, 46 \mathrm{mg}, 0.31 \mathrm{mmol})$ in THF $(0.8 \mathrm{~mL})$. After stirring for $1 \mathrm{~h}$ at room temperature, a solution of azetidinone derivative $(7,63 \mathrm{mg}, 0.24 \mathrm{mmol})$ in THF $(1 \mathrm{~mL})$ was added to the mixture, and stirred for $3 \mathrm{~h}$ at
$60{ }^{\circ} \mathrm{C}$. After cooling, the reaction mixture was treated with $\mathrm{H}_{2} \mathrm{O}(20 \mathrm{~mL})$ and extracted with $\mathrm{CH}_{2} \mathrm{Cl}_{2}(2 \times 20 \mathrm{~mL})$, and the organic layers were washed with $5 \%$ brine $(2 \times 20 \mathrm{~mL})$. The combined organic layers were dried over $\mathrm{MgSO}_{4}$, filtered, and concentrated in vacuo to give an oily residue. Purification of the residue by column chromatography afforded the title compound $(\mathbf{3 b}, 14 \mathrm{mg}, 17 \%$, cis-/trans-isomer $=3 /$ 1). ${ }^{1} \mathrm{H}$ NMR $\left(\mathrm{CDCl}_{3}, 80 \mathrm{MHz}\right)$, for cis-3b: $\delta 7.21(\mathrm{~s}, 5 \mathrm{H})$, 6.51 (br s, $1 \mathrm{H}), 6.18$ (br s, $1 \mathrm{H}), 4.92(\mathrm{~d}, J=2.5 \mathrm{~Hz}, 1 \mathrm{H}), 4.34$ (dd, $J=8.0,2.5 \mathrm{~Hz}, 1 \mathrm{H}), 3.61$ (s, $3 \mathrm{H}), 3.56(\mathrm{~s}, 2 \mathrm{H}), 2.50$ (s, $2 \mathrm{H}), 1.38(\mathrm{~s}, 6 \mathrm{H})$; for trans-3b: $\delta 7.25(\mathrm{~s}, 5 \mathrm{H}), 6.30-5.89(\mathrm{br}$ s, $2 \mathrm{H}), 5.50(\mathrm{dd}, J=8.0,5.0 \mathrm{~Hz}, 1 \mathrm{H}), 4.98(\mathrm{~d}, J=5.0 \mathrm{~Hz}$, $1 \mathrm{H}), 3.61(\mathrm{~s}, 3 \mathrm{H}), 3.56(\mathrm{~s}, 2 \mathrm{H}), 2.48(\mathrm{~s}, 2 \mathrm{H}), 1.38$ (s, 6H); IR $(\mathrm{KBr}) \vee 3400,1780,1745,1690 \mathrm{~cm}^{-1}$.

4(S)-Acetoxy-3(S)-phenylacetamidoazetidin-2-one (trans7). ${ }^{7,20}$ The synthesis of 7 was achieved through a three-step sequence, as previously described. ${ }^{7}$ First, the potassium salt of penicillin $\mathrm{G}(\mathbf{8}, 1.8 \mathrm{~g}, 4.8 \mathrm{mmol})$ in DMF $(16 \mathrm{~mL})$ was reacted with benzyl bromide $(0.64 \mathrm{~mL}, 5.4 \mathrm{mmol})$ for $2 \mathrm{~h}$ at room temperature to afford the benzyl ester of penicillin $\mathrm{G}$ $(1.7 \mathrm{~g})$. Second, this ester was added in small portions to a preheated solution $\left(80-85^{\circ} \mathrm{C}\right)$ of mercuric acetate $(1.9 \mathrm{mg}$, $6.0 \mathrm{mmol})$, acetic acid $(8.5 \mathrm{~mL})$, and acetic anhydride $(0.85$ $\mathrm{mL}$ ), and stirring was continued for $2 \mathrm{~h}$ at $80-85^{\circ} \mathrm{C}$ to give trans-(4S)-acetoxy-1-(benzyloxycarbonyl-2-methylpropenyl)-(3S)-phenylacetamidoazetidin-2-one (1.1 g). Third, this compound was allowed to undergo ozonolysis by bubbling ozone in a mixture of methanol- $\mathrm{CH}_{2} \mathrm{Cl}_{2}(1: 1,22 \mathrm{~mL})$ for $2 \mathrm{~h}$ at $-78{ }^{\circ} \mathrm{C}$ to provide the title compound $(7,0.50 \mathrm{~g}, 40 \%$ for three steps). The spectral data of 7 were in good agreement with the reported results. ${ }^{7}$

4-Acetoxyazetidin-2-one (9). ${ }^{7,19}$ As previously described, ${ }^{7}$ chlorosulfonyl isocyanate $(1.0 \mathrm{~mL}, 11 \mathrm{mmol})$ was reacted with vinyl acetate $(5.0 \mathrm{~mL}, 54 \mathrm{mmol})$ in dry $\mathrm{CH}_{2} \mathrm{Cl}_{2}$ for $2 \mathrm{~h}$ at $0^{\circ} \mathrm{C}$, leading to the generation of the title compound $(9$, $0.50 \mathrm{~g}, 35 \%)$. The spectral data of 9 were in good agreement with the reported results. ${ }^{7}$

Acknowledgments. This Research was supported by the Duksung Women's University Research Grant 2012.

\section{References}

1. Howarth, T. T.; Brown, A. G.; King, T. T. Chem. Commun. 1976, 266.

2. Imada, A.; Kitano, K.; Kintaka, K.; Muroi, M.; Asai, M. Nature 1981, 289, 590 .

3. Sykes, R. B.; Cimarusti, C. M.; Bonner, D. P.; Bush, K.; Floyd, D. M.; Koster, W. H. Nature 1981, 291, 489.

4. Burnett, D. A. Curr. Med. Chem. 2004, 11, 1873.

5. Sperka, T.; Pitlik, J.; Bagossi, P.; Tozser, J. Bioorg. Med. Chem. $\mathbf{2 0 0 5}, 15,3086$.

6. Galletti, P.; Giacomini, D. Curr. Med. Chem. 2011, 18, 4265.

7. Lee, S. H. Bull. Korean Chem. Soc. 2013, 34, 121.

8. Fan, H.-J.; Paternotte, I.; Vermander, M.; Li, K.; Beaujean, M.; Scorneaux, B.; Dumont, P.; Osinski, P.; Claesen, M.; Tulkens, P. M.; Sonveaux, E. Bioorg. Med. Chem. Lett. 1997, 7, 3107.

9. Nobuharu, K.; Ken-Ichi, N.; Akihisa, Y.; Syohei, N.; Susumu, N.; Satoshi, T.; Hiroshi, M.; Toshiyuki, K.; Masayasu, K.; Kazuhiko, K. Chem. Pharm. Bull. 1984, 32, 692. 
10. Meiries, S.; Marquez, R. J. Org. Chem. 2008, 73, 5015.

11. Khatik, G. L.; Kumar, R.; Chakraborti, A. K. Org. Lett. 2006, 8, 2433.

12. Shono, T.; Mataumura, Y.; Kashimura, S.; Hatanaka, K. J. Am. Chem. Soc. 1979, 101, 4752.

13. Greene A. E.; Padilla, A.; Crabbe, P. J. Org. Chem. 1978, 43, 4377.

14. Walton, E.; Wagner, A. F.; Bachelor, F. W.; Peterson, L. H.; Holly, F. W.; Folkers, K. J. Am. Chem. Soc. 1955, 77, 5144.

15. Yuan, M.; Zhitomirsky, D.; Adinolfi, V.; Voznyy, O.; Kemp, K. W.; Ning, Z.; Lan, X.; Xu, J.; Kim, J. Y.; Dong, H.; Sargent, E. H. Adv. Mater. 2013, 25, 5586.

16. Kim, H. R.; Kim, J. J.; Park, J. J.; Lee, S. H. Bioorg. Med. Chem. 2012, 20, 5720.

17. Kumar, I.; Jolly, R. S. Org. Lett. 2001, 3, 283.
18. Okuno, H.; Uoto, K.; Tomohiro, T.; Youinou, M. T. J. Chem. Soc. Dalton Trans.: Inorg. Chem. 1990, 11, 3375.

19. Firestone, R. A.; Barker, P. A.; Pisano, J. M.; Ashe, B. M.; Dahlgren, M. E. Tetrahedron 1990, 46, 2255.

20. Brain, E. G.; Eglington, A. J.; Nayler, J. H. C.; Pearson, M. J.; Southgate, R. J. Chem. Soc. Perkin Trans. I 1976, 447.

21. Ceric, H.; Kovacevic, M.; Sindler-Kulyk, M. Tetrahedron 2000, $56,3985$.

22. Corbett, D. F.; Kaura, A. C.; Maycock, C. D.; Stoodley, R. J. J. Chem. Soc. Perkin Trans. I 1987, 2009.

23. Kostova, M. B.; Myers, C. J.; Beck, T. N.; Plotkin, B. J.; Green, J. M.; Boshoff, H. I.; Barry, C. E., III.; Deschamps, J. R.; Konaklieva, M. I. Bioorg. Med. Chem. 2011, 19, 6842.

24. Fujimoto, K.; Iwano, Y.; Hirai, K. Tetrahedron Lett. 1985, 26, 89. 